\title{
Rapid health assessments of evacuation centres in areas affected by Typhoon Haiyan
}

\author{
Ruth Alma Ramos, ${ }^{\text {ab }}$ Vikki Carr de los Reyes, ${ }^{b}$ Ma Nemia Sucaldito ${ }^{b}$ and Enrique Tayag ${ }^{b}$ \\ Correspondence to Ruth Alma Ramos (email: ruthmd_ramos@yahoo.com).
}

Introduction: Typhoon Haiyan caused thousands of deaths and catastrophic destruction, leaving many homeless in Region 8 of the Philippines. A team from the Philippine Field Epidemiology Training Program conducted a rapid health assessment survey of evacuation centres severely affected by Haiyan.

Methods: A descriptive study was conducted whereby a convenience sample of evacuation centres were assessed on the number of toilets per evacuee, sanitation, drinking-water, food supply source and medical services.

Results: Of the 20 evacuation centres assessed, none had a designated manager. Most were located in schools (70\%) with the estimated number of evacuees ranging from 15 to 5000 per centre. Only four (20\%) met the World Health Organization standard for number of toilets per evacuee; none of the large evacuation centres had even half the recommended number of toilets. All of the evacuation centres had available drinking-water. None of the evacuation centres had garbage collection, vector control activities or standby medical teams. Fourteen (70\%) evacuation centres had onsite vaccination activities for measles, tetanus and polio virus. Many evacuation centres were overcrowded.

Conclusion: Evacuation centres are needed in almost every disaster. They should be safely located and equipped with the required amenities. In disaster-prone areas such as the Philippines, schools and community centres should not be designated as evacuation centres unless they are equipped with adequate sanitation services.

mmediately after a disaster, a rapid health assessment is usually conducted to determine basic health needs of the affected population to identify response priorities. Without rapid assessments, significant gaps or overlapping assistance may occur that can further burden the affected population. ${ }^{1}$ Rapid health assessments have been conducted by the Philippine Field Epidemiology Training Program (FETP) since 1990 for events such as typhoons, volcanic eruptions, flash floods and manmade disasters such as a chemical spill from a sunken ship, a trash slide in a dump site and the post-armed conflict in Zamboanga City.

Prior to Typhoon Haiyan in November 2013, evacuation centres in schools, churches and public buildings were designated by the local government, and the public was encouraged to evacuate. In November 2013, two weeks after Typhoon Haiyan, a team from the Philippine FETP conducted a rapid health assessment of evacuation centres in Region 8 to assess the health needs of the affected population, to inspect the facilities available at each evacuation centre and to make recommendations for improvements to evacuation centres.

\section{METHODS}

We conducted rapid health assessments between 22 November and 1 December 2013, two weeks after Typhoon Haiyan's landfall. We used the health assessment tool that had been developed by previous FETP fellows, although additional variables were added that were specific to the Haiyan response. The assessment tool collected information on demographics, nutritional and immunization status of the evacuees, food and water sources, living conditions, health services and environmental sanitation of each evacuation centre. A guide on data collection, including the definition of terms, was produced and distributed to all assessors. Two teams of five members conducted the evaluations.

\footnotetext{
Field Epidemiology Training Program, Epidemiology Bureau, Department of Health, Sta Cruz, Manila, Philippines.

Department of Health, Sta Cruz, Manila, Philippines.

Submitted: 29 April 2015; Published: 6 November 2015

doi: 10.5365/wpsar.2015.6.2.HYN_003
} 
Figure 1. Location of evacuation centres assessed by type and population size, post-Typhoon Haiyan, Region 8 , the Philippines, November 2013

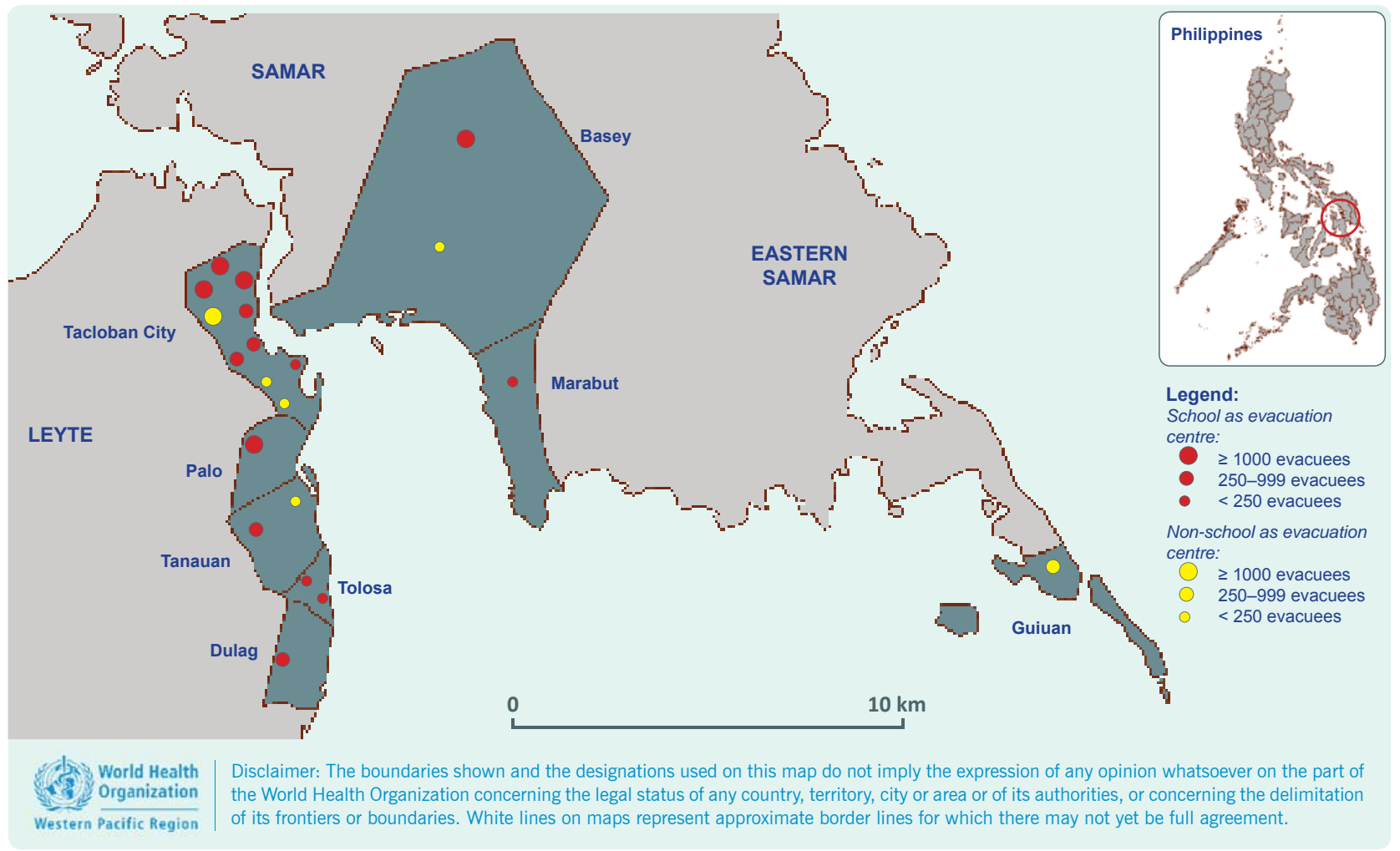

Twenty evacuation centres that were readily accessible in Region 8 (the area of maximum typhoon devastation) were selected by convenience sampling. Face-to-face interviews were conducted with either the village leader, school principal or a teacher, government staff and evacuees in each evacuation centre. Members of the evaluation team counted toilets, verified food and water sources and conducted a visual inspection. Evacuation centres were divided into large $(\geq 1000$ evacuees), medium (250-999) and small $(<250)$ facilities. The number of toilets was compared to the World Health Organization (WHO) standard for toilet volume (1 latrine:20 people). ${ }^{2}$ Data were entered and analysed using Microsoft Excel.

\section{RESULTS}

Of the 20 evacuation centres assessed, 14 (70\%) were schools and six (30\%) non-schools (tent city, church, orphanage, civic/convention centres and barge). The estimated number of evacuees in each evacuation centre ranged from 15 to 5000 (Figure 1). There were six large, six medium and eight small evacuation centres (Table 1).
None of the evacuation centres had a designated manager or a registry list of evacuees. Therefore data on the age, gender, former residence or health status of evacuees were unavailable. Similarly, documentation of the number of deaths, number of injuries and number of medical consultations was not available, even in centres where medical consultation teams had visited.

Four of the 20 evacuation centres (20\%) met the WHO standard for number of toilets. Nine (45\%) had at least half the recommended number of toilets; none of the large evacuation centres had at least half the recommended number of toilets. Two of the 14 schools (14\%) and two of the six non-schools (33\%) had an adequate number of toilets per evacuee (Table 1 ).

All evacuation centres had available drinkingwater; nine (45\%) had a functioning local water system, three had rationed bottled water, five were using water bladders (refilled with local spring water), one was using collapsible refillable water containers and one had a deep well (Table 1). None of the evacuation centres had performed post-disaster water quality testing at the time of assessment. 
Table 1. Needs assessment and services available in evacuation centres post-Typhoon Haiyan, Region 8, the Philippines, November 2013

\begin{tabular}{|c|c|c|c|c|c|c|c|c|c|c|c|}
\hline \multirow{2}{*}{$\begin{array}{l}\text { Estimated } \\
\text { population }\end{array}$} & \multicolumn{3}{|c|}{ Evacuation centres } & \multicolumn{8}{|c|}{ Services available } \\
\hline & No. & Type & Population & $\begin{array}{c}\text { Toilet: } \\
\text { population* }\end{array}$ & Water source & $\begin{array}{l}\text { Food } \\
\text { supply }\end{array}$ & $\begin{array}{l}\text { Garbage } \\
\text { collection }\end{array}$ & $\begin{array}{l}\text { Vector } \\
\text { control }\end{array}$ & $\begin{array}{c}\text { Standby } \\
\text { medical team }\end{array}$ & $\begin{array}{l}\text { Immunization } \\
\text { activities }^{\dagger}\end{array}$ & $\begin{array}{l}\text { Mental } \\
\text { health }\end{array}$ \\
\hline \multirow{6}{*}{$\begin{array}{c}\text { Large } \\
(\geq 1000)\end{array}$} & 1 & School & 5000 & $1: 179$ & Water bladder & Regular & None & None & None & Yes & No \\
\hline & 2 & School & 1132 & $1: 75$ & Bottled water & No & None & None & None & Yes & No \\
\hline & 3 & School & 1200 & $1: 43$ & $\begin{array}{l}\text { Collapsible } \\
\text { container }\end{array}$ & No & None & None & None & Yes & No \\
\hline & 4 & School & 2000 & $1: 77$ & Local system & Regular & None & None & None & No & Yes \\
\hline & 5 & $\begin{array}{l}\text { Convention } \\
\text { centre }\end{array}$ & 2000 & $1: 111$ & Water bladder & Regular & None & None & None & Yes & No \\
\hline & 6 & School & 1000 & $1: 91$ & Deep well & Regular & None & None & None & Yes & No \\
\hline \multirow{6}{*}{$\begin{array}{l}\text { Medium } \\
(250-999)\end{array}$} & 7 & School & 910 & $1: 25$ & Local system & Regular & None & None & None & No & No \\
\hline & 8 & School & 637 & $1: 40$ & $\begin{array}{l}\text { Rationed } \\
\text { bottled water }\end{array}$ & No & None & None & None & Yes & No \\
\hline & 9 & School & 421 & $1: 42$ & Local system & No & None & None & None & Yes & No \\
\hline & 10 & School & 473 & $1: 59$ & Local system & Sporadic & None & None & None & Yes & No \\
\hline & 11 & School & 250 & $1: 13$ & Local system & Regular & None & None & None & Yes & No \\
\hline & 12 & Tent city & 427 & $1: 15$ & Water bladder & Regular & None & None & None & No & Yes \\
\hline \multirow[t]{8}{*}{$\begin{array}{c}\text { Small } \\
(<250)\end{array}$} & 13 & $\begin{array}{l}\text { Civic } \\
\text { centre }\end{array}$ & 200 & $1: 200$ & Local system & Sporadic & None & None & None & Yes & No \\
\hline & 14 & Barge & 200 & $1: 20$ & Local system & No & None & None & None & No & No \\
\hline & 15 & Orphanage & 120 & $1: 60$ & Local system & No & None & None & None & Yes & Yes \\
\hline & 16 & Church & 100 & $1: 100$ & $\begin{array}{l}\text { Rationed water } \\
\text { from DSWD }\end{array}$ & Regular & None & None & None & No & No \\
\hline & 17 & School & 80 & $1: 27$ & Water bladder & Sporadic & None & None & None & Yes & No \\
\hline & 18 & School & 68 & $1: 34$ & Local system & No & None & None & None & Yes & No \\
\hline & 19 & School & 15 & $1: 4$ & Water bladder & Sporadic & None & None & None & Yes & No \\
\hline & 20 & School & 45 & $1: 23$ & $\begin{array}{l}\text { Rationed } \\
\text { bottled water }\end{array}$ & Sporadic & None & None & None & No & No \\
\hline
\end{tabular}

* WHO Standard is 1 toilet to 20 people. $^{3}$

Immunization activities include measles, tetanus and oral polio virus vaccination.

DSWD, Department of Social Welfare and Development.

Seven (35\%) evacuation centres did not provide food to evacuees, including two of the five large evacuation centres (40\%). Four of the eight (50\%) small evacuation centres provided food irregularly. None of the evacuation centres had garbage collection, vector control activities or standby medical teams (Table 1 ).

Fourteen (70\%) evacuation centres had onsite vaccination activities for measles, tetanus and polio. Four of the five (80\%) large evacuation centres conducted vaccination activities. Three evacuation centres (15\%) had mental health services and psychosocial services (Table 1).

Many evacuation centres appeared overcrowded. At one evacuation centre at a school in Tacloban City, there was an average of 10 families per room. Some schools serving as evacuation centres were also damaged by the typhoon.

\section{DISCUSSION}

In a study of the 2011 Great East Japan Earthquake, it was found that three factors influenced the health of evacuees: (1) presence of persons in charge of providing health services; (2) size of evacuation centre; and (3) status of water supply. ${ }^{3}$ In this study, there were no managers at any evacuation centre and no list of evacuees. The size of the evacuation centres varied, yet the supply of drinking-water was adequate.

Although managing evacuation centres is a local government unit's responsibility in the Philippines, most of the affected municipalities suffered loss of staff as a 
result of Haiyan and so their capacity to provide services was diminished. Having managers who monitored the migration in and out of evacuation centres and the services that were being provided would have allowed for initial health assessments to provide better information on the population. Managers could also have assisted in the efficient provision of services from governmental health staff and nongovernmental organizations. In a survey conducted in evacuation centres two weeks after the Great East Japan Earthquake, ${ }^{3}$ it was found that promptly placing persons in charge of health matters at evacuation centres was a practicable and effective measure, and allocating of at least one such person per 50 evacuees was desirable. Another study reported that initially after an earthquake, most evacuation centres were managed by local teachers or volunteers; however, as the evacuation period lengthened, evacuees themselves started taking initiatives to manage the centres. $^{4}$

The size of evacuation centres was an important determinant of quality of services provided in Japan post-disaster, ${ }^{3}$ with smaller centres offering better health conditions for residents. Smaller centres seemed to function better due to better interpersonal relationships and an environment that enabled the emergence of strong leadership. ${ }^{5}$ In our study, service quality varied among centres of all sizes, with the large centres providing good vaccination services but limited food and poor sanitation services. None of the evacuation centres had garbage disposal or vector control activities; therefore, evacuees were at risk of contracting diarrhoeal and vector-borne diseases. The situation of overcrowding in evacuation centres and presence of breeding sites for mosquitoes may lead to increased transmission of diseases with the potential for large outbreaks.

Although all evacuation centres in this study had access to water, no water quality testing had been conducted at the time of the assessments. Minimum standards for humanitarian services include not only a sufficient quantity of water but also disinfection of the water sources to reduce risk of contamination and the threat of an outbreak of diarrhoeal disease. ${ }^{6}$ Food supply varied in evacuation centres. Lack of food is particularly problematic in large evacuation centres where alternative sources of food may be limited. Food was more commonly supplied to school evacuation centres compared with non-school centres.

Following the 2004 tsunami in Aceh, Indonesia, community-based health evaluations concluded that access to sanitation and clean water as well as primary care services were the most essential healthrelated services. ${ }^{7}$ One toilet per 20 individuals is the recommended ratio in an evacuation centre housing people for more than a few days, ${ }^{2}$ yet in our study, none of the large evacuation centres met this recommended ratio. Schools are often used as evacuation centres in the Philippines as these are thought to have the capacity to shelter large numbers of people. However, toilet volume in schools is designed to accommodate a specific number of students for a limited number of hours each day. Only $14 \%$ of schools had the recommended number of toilets per person.

There were some limitations to this study. The assessments were conducted quickly, therefore, accuracy of the data may have been compromised. Managers were not in place in evacuation centres; hence, the information obtained was prone to bias as many estimates were used. There could have been an underestimation of the volume of services needed because only an estimation of population figures was used. The centres were purposively chosen and therefore may not have been representative of all evacuation centres. Certain centres were not assessed due to issues of access and security.

Evacuation centres are needed in almost every disaster. In disaster-prone areas in the Philippines, evacuation centres should be safely located and equipped with adequate services and a proper management structure. As evacuation centres are already identified in every municipality in the Philippines, we recommend that a management team be assigned to each evacuation centre with staff from municipal health offices and rural health units. Since schools are primarily used as evacuation centres in the Philippines, school principals or head teachers could also be on the management team. Only schools equipped with adequate sanitation services should be used as evacuation centres.

Registration and information management is important in every evacuation centre. A logbook should 
be available at all evacuation centres to register all evacuees indicating the name, age, sex, family head, place of origin and members of the family. This would give details on the profile of disaster victims and of family members with special needs. The goal of better managed evacuation centres can be achieved through advanced planning and preparation that include welldefined leadership and responsibility.

\section{Conflicts of interest}

None declared.

\section{Funding}

None.

\section{Acknowledgements}

We are grateful for the cooperation and support of the head and staff of Regional Epidemiology and Surveillance Unit from Region 8, FETP Batches 23 and 24 and FETP graduates who conducted these assessments and the partcipants from the evacuation centres.
We also thank Dr Michael O’Reilly for his review.

\section{References}

1. Arii M. Rapid assessment in disasters. Japan Medical Association Journal, 2013, 56(1):19-24 (https://www. med.or.jp/english/journal/pdf/2013_01/019_024.pdf, accessed 18 August 2015).

2. Rapid health assessment protocols for emergencies. Geneva, World Health Organization, 1999 (http://www.wpro.who.int/ vietnam/publications/rapid health assessment protocols.pdf, accessed 18 August 2015).

3. Tokuda $\mathrm{K}$ et al. A survey conducted immediately after the 2011 Great East Japan Earthquake: evaluation of infectious risks associated with sanitary conditions in evacuation centers. Journal of Infection and Chemotherapy, 2014, 20:498-501. doi:10.1016/j.jiac.2014.04.012 pmid:24861538

4. Ranghieri $\mathrm{F}$, Ishiwatari $\mathrm{M}$, editors. Learning from megadisaster: lessons from the Great East Japan Earthquake. Washington, DC, The World Bank, 2014 (https://openknowledge.worldbank.org/ handle/10986/18864, accessed 18 August 2015).

5. The Great East Japan Earthquake: a story of a devastating natural disaster, a tale of human compassion. Manila, World Health Organization Regional Office for the Western Pacific, 2012 (http:// www.wpro.who.int/publications/docs/japan_earthquake.pdf, accessed 18 August 2015).

6. Humanitarian charter and minimum standards in disaster response. Geneva, The Sphere Project, 2011 (http://www. sphereproject.org/, accessed 18 August 2015).

7. Brennan RJ, Rimba K. Rapid health assessment in Aceh Jaya District, Indonesia, following the December 26 tsunami. Emergency Medicine Australasia, 2005, 17:341-350. doi:10.1111/j.17426723.2005.00755.x pmid:16091096 